\title{
Modification and Characterization of Biodegradable Chitosan/ Starch-Based Films with Monomer 1,4-Butanediol Diacrylate (BDDA) by Gamma Radiation
}

\author{
Nousin Akter ${ }^{1,2}$, Suvanker Saha², Farah M.J. Hossain², Fahad B. Quader ${ }^{1,2}$, \\ Poonam Alamgir ${ }^{1}$ and Ruhul A. Khan ${ }^{1, *}$ \\ ${ }^{1}$ Institute of Radiation and Polymer Technology, Bangladesh Atomic Energy Commission, GPO Box: 3787, \\ Dhaka-1000, Bangladesh \\ ${ }^{2}$ Department of Applied Chemistry and Chemical Engineering, University of Dhaka, Dhaka-1000, Bangladesh
}

\begin{abstract}
Chitosan reinforced starch-based biodegradable films were prepared by solution casting. Tensile strength (TS), tensile modulus (TM), elongation at break (\%), and water vapor permeability (WVP) of the $50 \%$ chitosan containing starch-based films were found to be $47 \mathrm{MPa}, 550 \mathrm{MPa}, 16 \%$, and $2.45 \mathrm{~g} \cdot \mathrm{mm} / \mathrm{m}^{2} \cdot$ day $\cdot \mathrm{kPa}$, respectively. Monomer 1,4 butanediol diacrylate (BDDA) was added $(0.25-1 \%$ by wt) to the starch/chitosan (50:50) based film formulation. Then, films were cast and gamma irradiated from a radiation dose varied from $1 \mathrm{kGy}$ to $25 \mathrm{kGy}$. Then mechanical and barrier properties were evaluated. The highest TS $(80 \mathrm{MPa})$ and TM $(880 \mathrm{MPa})$ of the films were found by using $0.5 \%$ monomer at $5 \mathrm{kGy}$ dose. The WVP of the films were found to be $1.50 \mathrm{~g} \cdot \mathrm{mm} / \mathrm{m}^{2} \cdot$ day $\cdot \mathrm{kPa}$ which is $38.77 \%$ lower than control starch/chitosan-based films. Molecular interactions due to incorporation of BDDA were supported by Fourier transform infra red (FTIR) spectroscopy. The water uptake of the films pointed out better hydrophobic character due to incorporation of BDDA in starch/chitosan-based films. Surface morphologies of BDDA treated films were examined by scanning electron microscope (SEM) and suggested better morphologies due to BDDA treatment with starch/chitosanbased biodegradable films.
\end{abstract}

Keywords: Starch, chitosan, biopolymer, monomer, biodegradable, gamma radiation.

\section{INTRODUCTION}

Biodegradable polymeric materials have excellent and promising properties for the applications in packaging sectors. Besides the inherent biodegradability of these materials, there are other important properties like higher strength, transparency, low cost, and excellent film-forming properties via casting. It is, therefore, of industrial interest to increase the overall performance of these materials in order to generate value added product to counteract negative issues such as current pricing to enable their substitution for more well-established petroleum-based materials. In this context, modifications by monomers via gamma radiation have a significant potential to enhance mechanical and barrier properties of these materials. Petroleum-based synthetic polymers are being using as packaging materials due to their excellent thermo-mechanical properties and low cost. But these materials are not biodegradable. Therefore, research works are in progress to develop alternative packaging materials which are environment-friendly, and possess good thermo-mechanical and barrier properties. In recent years, there has been a marked

*Address correspondence to this author at the Institute of Radiation and Polymer Technology, Bangladesh Atomic Energy Commission, GPO Box: 3787, Dhaka-1000, Bangladesh; Tel: +8801814348838; Fax: +88027701337; E-mail:dr.ruhul_khan@yahoo.com increase in interest in the use of biodegradable materials for packaging applications. A number of blends using bio-polymers can be the alternative of currently used synthetic polymeric materials. The most common and potential bio-polymers are starch, chitosan, alginate, gelatin etc. It is expected that these biodegradable polymeric materials will reduce the use of synthetic non-biodegradable polymeric materials and thus reduce the environmental pollution [1-5].

Starch is the most abundant naturally occurring polymer, a truly renewable resource, and it is a biodegradable polymer because it can readily be metabolized by a wide range of microorganisms. Unlike other synthetic thermoplastic polymers, starch can be processed into a thermoplastic material in the presence of plasticizers and under the influence of heat. The most important sources of starch are wheat, potato, rice, tapioca, and corn. Starch is a polysaccharide; it is composed of glucose monomers. Starch is a potentially interesting biodegradable polymeric material due to its availability, low cost and renewability. Moreover, the use of starch in the plastics industry can reduce dependence on synthetic polymers. In fact, starch is not truly a thermoplastic like most of the synthetic polymers. Starch is also a type of carbohydrate polymer and consisting of a large number of glucose units joined together by glycosidic bonds. Starch is a widely useful polymeric material for making 
biodegradable plastics, but pure starch-based films possess low mechanical properties. To improve the drawbacks, blending of starch or its derivatives with various thermoplastic polymers is being investigated [610].

Among biodegradable films, a considerable attention has been given to chitosan because of its unique properties. Chitosan $[\beta-(1,4)-2$-amino-2-deoxyd-glucopyranose] is a biopolymer derived by deacetylation of chitin which is the second most abundant biopolymer in nature after cellulose. Chitin is present in the exoskeleton of arthropods such as insects, crabs, shrimps, lobsters and certain fungal cell walls. A significant research works has been done using chitosan in different fields [11-13]. The presence of active groups in chitosan molecules favored it to use in many fields. Chitosan has been reported as a potential polymeric material for food packaging, especially as edible films and coatings due to its excellent film forming properties. Because of reactive amino and hydroxyl functional groups, chitosan is frequently blended with other polymers or cross-link to improve their functional properties by inducing inter- or intra-molecular cross-linking in the polymer matrix [1416].

The objective of the present research was to make biodegradable films for packaging applications using chitosan and starch via solution casting. Chitosan was used as the reinforcing agent in starch-based films then mechanical and barrier properties were evaluated.

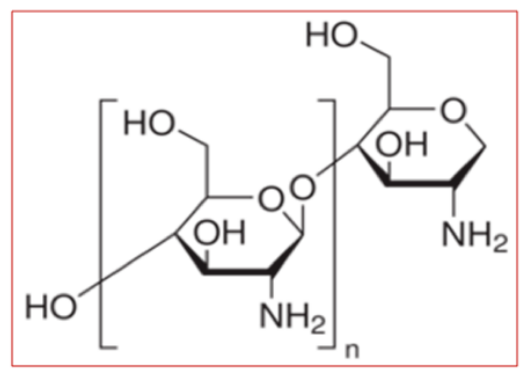

Chitosan
Monomer 1,4 butanediol diacrylate (BDDA) was added to the starch/chitosan-based film formulation. Then, films were cast and gamma irradiated for grafting. Mechanical and barrier properties of the BDDA grafted films were evaluated. Molecular interactions due to incorporation of BDDA were studied by Fourier transform infra red (FTIR) spectroscopy. Water uptake behavior of the grafted films was compared with native chitosan and starch/chitosan films. Surface morphologies of the films were examined by scanning electron microscope (SEM).

\section{EXPERIMENTAL SECTION}

\subsection{Materials}

Chitosan from crab shell (powder form; viscosity of $200 \mathrm{cP}$ ), starch (from potato, powder form), and monomer (BDDA), were purchased from Sigma-Aldrich Chemie $\mathrm{GmbH}$, Germany. The chemical structure of chitosan, starch, and BDDA is given in Figure 1.

\subsection{Preparation of Biopolymeric Films by Casting}

At first, $1 \%$ chitosan solution $(\mathrm{w} / \mathrm{w})$ was prepared using $2 \%(\mathrm{w} / \mathrm{w})$ acetic acid solution. Films of chitosan were prepared by casting the chitosan solution onto flat silicon-coated Petri dishes and allowed to dry for $24 \mathrm{~h}$, at room temperature and at 35\% relative humidity. Dried films were peeled off manually using spatula and stored in the desiccator prior to characterization. Starch was dissolved in de-ionized hot $\left(70^{\circ} \mathrm{C}\right)$ water with constant stirring. Then starch and chitosan solutions

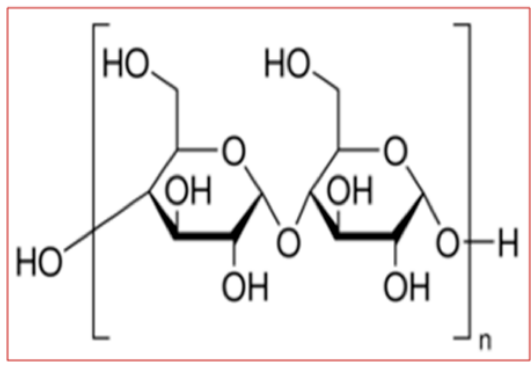

Starch

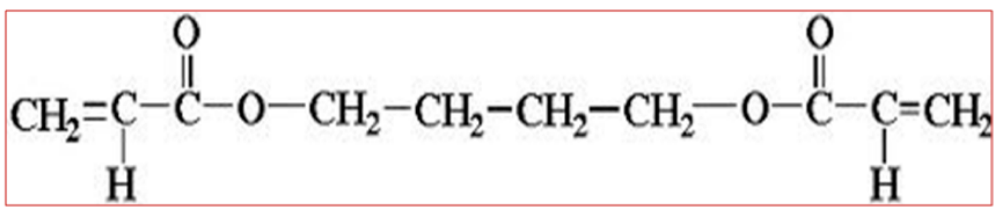

\section{1,4-Butanediol Diacrylate (BDDA)}

Figure 1: Chemical structure of chitosan, starch, and monomer BDDA. 
were mixed together at different proportions. Films were prepared by solution casting at the same parameters mentioned above. Thickness of films was maintained to $100 \mu \mathrm{m}$ by adding the same amount of formulation in the same size of the Petri dishes. Then BDDA was added in starch/chitosan (50:50)-based film formulation from $0.25 \%, 0.50 \%$ and $1 \%$ (by wt). The concentration of BDDA in dry films is given in Table 1.

\subsection{Mechanical Properties of the Films}

Mechanical properties (TS, TM, and Eb) of the films were investigated by the Universal Testing Machine (Hounsfield series $S$ testing machine, UK, H50 KS0404) with a crosshead speed of $1 \mathrm{mms}^{-1}$ at a span distance of $25 \mathrm{~mm}$. The dimensions of the test specimen were: $60 \mathrm{~mm} \times 15 \mathrm{~mm} \times 0.01 \mathrm{~mm}$. The experiment was carried out according to the European standard (ISO/DIS 527-1:2010).

\subsection{Water Uptake Tests of the Films}

Water uptake test of the films was carried out in deionized water at room temperature $\left(25^{\circ} \mathrm{C}\right)$. The test was carried out up to $60 \mathrm{~min}$. Samples were taken into glass beakers containing $100 \mathrm{ml}$ of deionized water. At set time points, samples were taken out from the beaker and wiped out properly and then reweighed. The water uptake was measured by a weight difference methodology. The equation for water uptake was as follows: Water uptake $(\%)=\left(W_{\text {wet }}-W_{\text {dry }}\right) / W_{\text {dry }} \times 100$, where $W_{\text {wet }}$ indicated the weight of the film after immersion in water and $W_{\text {dry }}$ represented the weight of the film before immersion.

\subsection{Fourier Transform Infra Red (FTIR) Spectroscopy}

FTIR spectra of the films were recorded using a Spectrum One spectrophotometer (Perkin-Elmer) equipped with an attenuated total reflectance (ATR) device for solids analysis and a high linearity lithium tantalate (HLLT) detector. Spectra were analyzed using the Spectrum 6.3.5 software. Films were stored at room temperature for 72 minutes in a desiccator containing saturated $\mathrm{NaBr}$ solution to ensure a stabilized atmosphere of $59.1 \% \mathrm{RH}$ at $20^{\circ} \mathrm{C}$. Films were then placed onto a zinc selenide crystal, and the analysis was performed within the spectral region of $650-4000 \mathrm{~cm}^{-1}$ with 16 scans recorded at a $4 \mathrm{~cm}^{-1} 10$ resolution. After attenuation of total reflectance and baseline correction, spectra were normalized with a limit ordinate of 1.5 absorbance units. Resulting FTIR spectra were compared in order to evaluate the effects of starch filling in the chitosan-based films, based on the intensity and shift of vibrational bands.

\subsection{Water Vapor Permeability (WVP)}

The WVP tests were conducted gravimetrically using an ASTM procedure [1]. Films were mechanically sealed onto Vapometer cells (No. 68-1, Twhing-Albert Instrument Company, West Berlin, NJ, USA) containing $30 \mathrm{~g}$ of anhydrous calcium chloride $(0 \% \mathrm{RH})$. The cells were initially weighed and placed in a Shellab 9010L controlled humidity chamber (Sheldon Manufacturing Inc., Cornelius, OR) maintained at $25^{\circ} \mathrm{C}$ and $60 \% \mathrm{RH}$ for $24 \mathrm{~h}$. The amount of water vapor transferred through the film and absorbed by the desiccant was determined from the weight gain of the cell. The assemblies were weighed initially and after $24 \mathrm{~h}$ for all samples and up to a maximum of $10 \%$ gain. Changes in weight of the cell were recorded to the nearest $10^{-4}$ g. WVP was calculated according to the combined Fick and Henry laws for gas diffusion through coatings and films, according to the equation: WVP $\left(\mathrm{g} \cdot \mathrm{mm} / \mathrm{m}^{2} \cdot\right.$ day. $\left.\mathrm{kPa}\right)=\Delta \mathrm{w} \cdot \mathrm{x} / \mathrm{A} \cdot \Delta \mathrm{P}$, where $\Delta \mathrm{w}$ is the weight gain of the cell $(\mathrm{g})$ after $24 \mathrm{~h}, \mathrm{x}$ is the film thickness $(\mathrm{mm}), A$ is the area of exposed film $(31.67 \times$ $10^{-4} \mathrm{~m}^{2}$ ), and $\Delta \mathrm{P}$ is the differential vapor pressure of water through the film $\left(\Delta \mathrm{P}=3.282 \mathrm{kPa}\right.$ at $\left.25^{\circ} \mathrm{C}\right)$.

\subsection{Scanning Electron Microscopy Analysis (SEM)}

Film samples $(5 \times 5 \mathrm{~mm})$ were deposited on an aluminum holder and sputtered with gold-platinum (coating thickness, 150-180 A) in a Hummer IV sputter coater. SEM photographs were taken with a Hitachi S-

Table 1: Concentration (wt\%) of BDDA in Starch/Chitosan-Based Films

\begin{tabular}{|c|c|c|c|c|}
\hline BDDA concentration in the formulation (wt\%) & \multicolumn{4}{|c|}{ Film Composition (wt\%) } \\
\cline { 2 - 5 } & Starch & Chitosan & BDDA & 0 \\
\hline \hline 0 & 50 & 50 & 11.11 & 100 \\
\hline 0.25 & 44.44 & 44.44 & 20 & 100 \\
\hline 0.5 & 40 & 40 & 33.33 & 100 \\
\hline 1 & 33.33 & 33.33 & & \\
\hline
\end{tabular}


4700 FEG-SEM scanning electron microscope (Hitachi Canada Ltd., Mississauga, ON, Canada) at a magnification of $40,000 \times$, at room temperature. The working distance was maintained between 15.4 and $16.4 \mathrm{~mm}$, and the acceleration voltage used was $5 \mathrm{kV}$, with the electron beam directed to the surface at a $90^{\circ}$ angle and a secondary electron imaging (SEI) detector.

\subsection{Irradiation}

Films were irradiated using a Co-60 gamma source (25 kci) of the Bangladesh Atomic Energy Commission, Savar, Dhaka, for different doses (1-25 kGy), at a dose rate of $3.50 \mathrm{kGy} / \mathrm{h}$.

\subsection{Statistical Analysis}

For each measurement, five samples in each replicate were tested. Analysis of variance and Duncan's multiple-range tests were used to perform statistical analysis of all results, using PASW Statistics Base 18 software (SPSS Inc., Chicago, IL, USA). Differences between means were considered to be significant when $p \leq 0.05$.

\section{RESULTS AND DISCUSSION}

\subsection{Mechanical and Barrier Properties of Starch/Chitosan-based Biodegradable Films}

Chitosan/starch-based biodegradable films were prepared by solution casting. The chitosan content varied from $20 \%$ to $80 \%$ (by wt.) in starch-based films to investigate the effectiveness of chitosan as reinforcing filler. Mechanical and barrier properties of chitosan/starch-based films are presented in Table 2. Tensile strength (TS) values of starch-based films was improved significantly $(p \leq 0.05)$ with the addition of chitosan. For $50 \%$ addition of chitosan, the TS values were observed to be $47 \mathrm{MPa}$. The starch-based films became brittle below $20 \%$ chitosan content. Therefore, in this investigation, the minimum amount of chitosan was maintained to $20 \%$ (by wt). It is to be noted here that only starch could not form films by solution casting. The TS of chitosan films was found to be $56 \mathrm{MPa}$ (denoted $100 \%$ chitosan). Chitosan has excellent film forming capability [14]. So, chitosan containing starchbased films were prepared easily by solution casting. Starch is comparatively cheaper than chitosan. So, biodegradable films were successfully prepared using starch and chitosan. The $50 \%$ chitosan content starchbased films were almost transparent but below $50 \%$ chitosan containing films was opaque. Similarly, tensile modulus (TM) values of starch-based films was also improved significantly $(p \leq 0.05)$ with the incorporation of chitosan. For $50 \%$ addition of chitosan, the TM values were observed to be $550 \mathrm{MPa}$, respectively. The increased TM values of the chitosan reinforced starch-based films may be attributed to the increased stiffness of the films by the addition of chitosan. TM is a measure of the stiffness of an elastic material and is a quantity used to characterize materials. So, it was found that addition of chitosan improved stiffness and strength of starch-based films. With the rise of strength and modulus, the Eb values of the starch-based films decreased monotonously due to chitosan addition. The Eb value of $50 \%$ chitosan content films was $16 \%$. Chitosan acted as a reinforcing agent in starch-based biodegradable films. Thus, higher content of chitosan can render the films stiffer. As a result, a decrease in Eb values was observed. Similar results were reported by Pinotti et al. [17] who indicated the reduction in flexibility of methylcellulose (MC) films with the increase of chitosan concentration. Khan et al. [18] reported that chitosan incorporation $(5-36 \%$ by $\mathrm{wt})$ in MC-based films significantly improved the strength with the reduction of viscoelasticity. The $50 \%$ chitosan containing starch-based films was considered as the optimum because the films had good strength (47 $\mathrm{MPa}$ ), modulus (550 MPa), and optimum Eb (16\%) values. Moreover, the appearance of the films was quite transparent.

The water vapor permeability of chitosan films and chitosan/starch-based films was measured. The values of WVP for chitosan films was found to be 3.30 $\mathrm{g} . \mathrm{mm} / \mathrm{m}^{2}$.day. $\mathrm{kPa}$. The values of WVP increased monotonously with increase of chitosan in starch-based films. The WVP values of $50 \%$ (by wt) of chitosan reinforced starch-based films were 2.45 g. $\mathrm{mm} / \mathrm{m}^{2}$.day.kPa. It was clearly reveled that chitosan reinforced films had lower WVP values compared to native chitosan film. For $50 \%$ chitosan containing films, the WVP reduced to $25.75 \%$ from native chitosan film. Reduction of WVP values indicated better barrier to water vapors of the films. The presence of chitosan in starch-based films could increase the tortuosity of the two biopolymers (chitosan and starch) leading to slower diffusion processes and hence, to a lower permeability [19]. The barrier properties are enhanced if the filler is less permeable and has a good dispersion into the matrix [20]. Owing to the higher amount of hydrogen bonds, most of the biodegradable polymeric films are hydrophilic, and that is responsible for poor barriers to water vapor [21]. The presence of chitosan in the starch-based composites is responsible for lower 
Table 2: Mechanical and Barrier Properties of Chitosan Reinforced Starch-Based Films

\begin{tabular}{|c|c|c|c|c|}
\hline $\begin{array}{l}\text { Chitosan } \\
\text { content }\end{array}$ & $\begin{array}{l}\text { Tensile Strength } \\
\text { (MPa) }\end{array}$ & $\begin{array}{l}\text { Tensile Modulus } \\
\text { (MPa) }\end{array}$ & $\begin{array}{l}\text { Elongation at Break } \\
(\%)\end{array}$ & $\begin{array}{c}\text { WVP } \\
\left(\mathrm{g} \cdot \mathrm{mm} / \mathrm{m}^{2} \cdot \text { day } \cdot \mathrm{kPa}\right)\end{array}$ \\
\hline 20 & 27 & 345 & 23 & 2 \\
\hline 30 & 30 & 395 & 22 & 2.12 \\
\hline 40 & 38 & 430 & 19 & 2.32 \\
\hline 50 & 47 & 550 & 16 & 2.45 \\
\hline 60 & 49 & 630 & 15 & 2.80 \\
\hline 70 & 50 & 695 & 13 & 2.95 \\
\hline 80 & 53 & 750 & 12 & 3.1 \\
\hline 100 & 56 & 840 & 11 & 3.3 \\
\hline
\end{tabular}

WVP values compared to control chitosan films. The WVP values of the chitosan reinforced starch-based composites indicated excellent barriers to water vapor.

\subsection{Mechanical Properties of the BDDA Containing Chitosan/Starch-Based Films}

The tensile strength (TS) values of BDDA containing chitosan/starch (50:50)-based films were studied as a function of gamma radiation dose and the results are presented in Figure 2. The TS of chitosan/starch-based films were found to be $47 \mathrm{MPa}$ (termed control in the figure). When control films (chitosan/starch) were irradiated from 1 to $25 \mathrm{kGy}$ doses, the film strength increased up to 3 kGy (51 $\mathrm{MPa}$ ) but after that a drastic reduction was observed (at 25 kGy, the TS was only 29). At low radiation, cross-linking may happen between chitosan molecules; and also between chitosan and starch. But at higher doses, radiation degradation occurred and strength decreased. Just addition (no irradiation) of BDDA in the films, the strength increased significantly. Addition of $0.25 \%, 0.50 \%$ and $1 \%$ of BDDA in the film formulation, the TS values reached to 51,56 and $50 \mathrm{MPa}$, respectively. Monomer BDDA did not react with chitosan/starch in absence of gamma radiation. The reason behind the increase of TS might be due to the mechanical bond between the monomer and biopolymers. But with the exposure of gamma radiation ( 1 to $25 \mathrm{kGy}$ ), the values of TS of the irradiated films changed significantly. The BDDA concentration in the films varied from $0.25 \%$ to $1 \%$ (by wt.) in film formulation (and $11 \%$ to $33 \%$ in dry condition). For

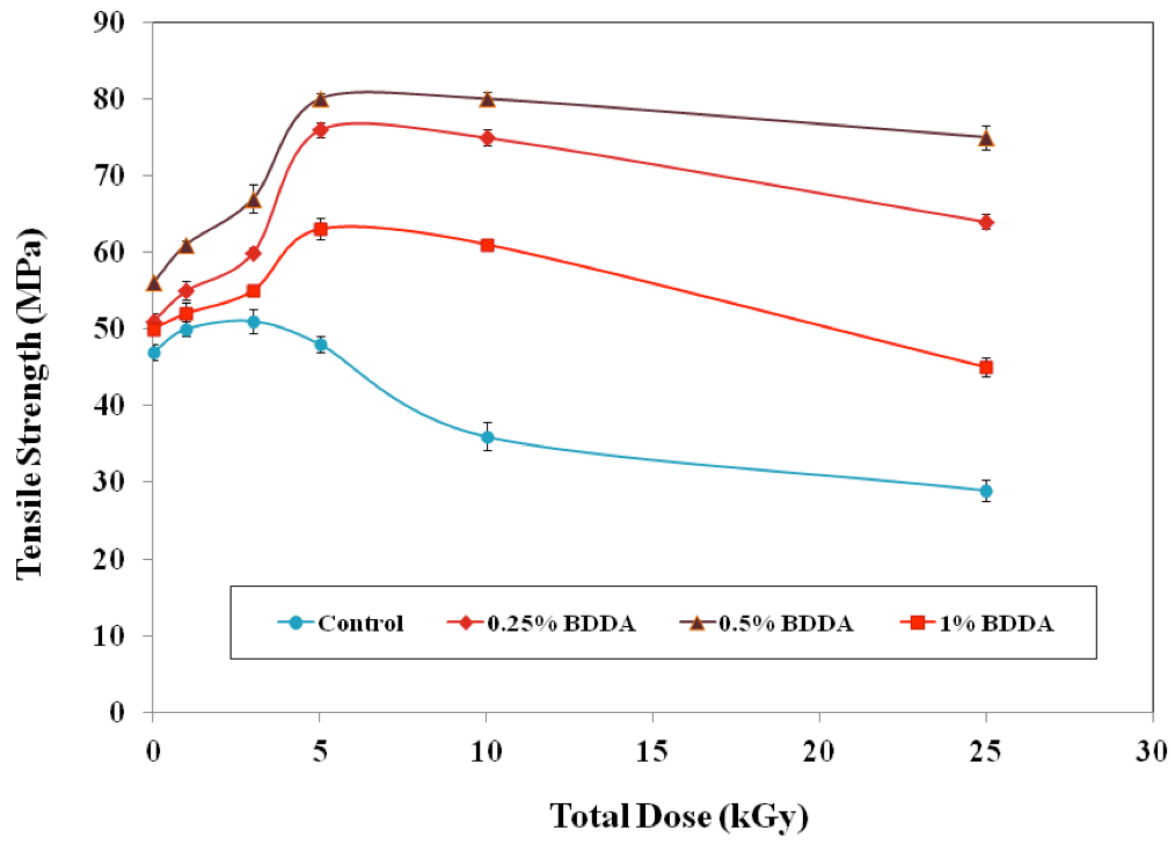

Figure 2: Effect of gamma radiation on tensile strength of starch+chitosan (50:50) films (control), and BDDA containing starch+chitosan-based films. 
different monomer concentrations, the TS values increased up to $5 \mathrm{kGy}$ of radiation dose and then decreased (from $10 \mathrm{kGy}$ ). The highest TS value was observed at $0.5 \%$ monomer concentration and at $5 \mathrm{kGy}$ dose. The highest TS value was found to be $80 \mathrm{MPa}$ which is significantly higher than control film (47 MPa). So, BDDA imparted $70.21 \%$ increase of strength of the chitosan/starch-based film. The monomer BDDA might be reacted with chitosan/starch molecules and thus TS of the films increased. But at higher monomer concentration, homo-polymer (BDDA+BDDA) could form and the TS values of the film decreased. Reactive sites could be initiated in the monomers when they were irradiated which enhances the possibility of creating chemical reaction between chitosan/starch and BDDA. The increase of grafting lead to the improvement of the TS values with increased gamma radiation. But at higher dose (25 kGy), the polymer degradation could happen and leading to the reduction of strength of the films. The hydroxyl group of biopolymers (chitosan and starch) could react with the vinyl group of BDDA during gamma radiation. The reaction mechanism is given in Figure 3 . It is reported [22] the hydroxyl group of phosphate glass fibers reacted with the vinyl group of 2-Hydroxyethyl methacrylate (HEMA) monomer during irradiation.

The tensile modulus (TM) of the BDDA added chitosan/starch-based films are cited in Figure 4 against total radiation dose as a function of different monomer concentrations. The TM of chitosan/starchbased films was found to be $550 \mathrm{MPa}$. Addition of BDDA in the films (not irradiated, at $0 \mathrm{kGy}$ ), the TM values of the films increased up to $3 \mathrm{kGy}$ then decreased. Addition of $0.25,0.50$, and $1 \%$ BDDA, the $\mathrm{TM}$ values of chitosan/starch-based films were found to be 600,650 , and $610 \mathrm{MPa}$ respectively. When BDDA containing chitosan/starch-based films were irradiated, the TM values increased with the increase of radiation dose (up to $5 \mathrm{kGy}$ ) and then decreased. For $5 \mathrm{kGy}$ dose, the TM values were found to be 780,880 , and $500 \mathrm{MPa}$ for $0.25,0.50$, and $1 \%$ BDDA concentrations, respectively. The $0.50 \%$ monomer containing films performed better TM values compared to other concentrations. The chitosan/starch-based films containing $0.5 \%$ BDDA at $5 \mathrm{kGy}$ dose showed the highest TM values. Monomer addition followed by irradiation treatment increased the TM values due to the cross linking reaction between the monomer and chitosan/starch. But at higher monomer concentration, the TM values decreased as the monomer recombination leads to homo-polymerization reaction. Moreover, with the increase of gamma radiation dose, the TM values increased since more free radicals were initiated with the irradiation treatment (ionizing radiation) which leads to the enhanced cross linking between BDDA and chitosan/starch-based.

The results of elongation at break (Eb) values of BDDA containing chitosan/starch-based films as a

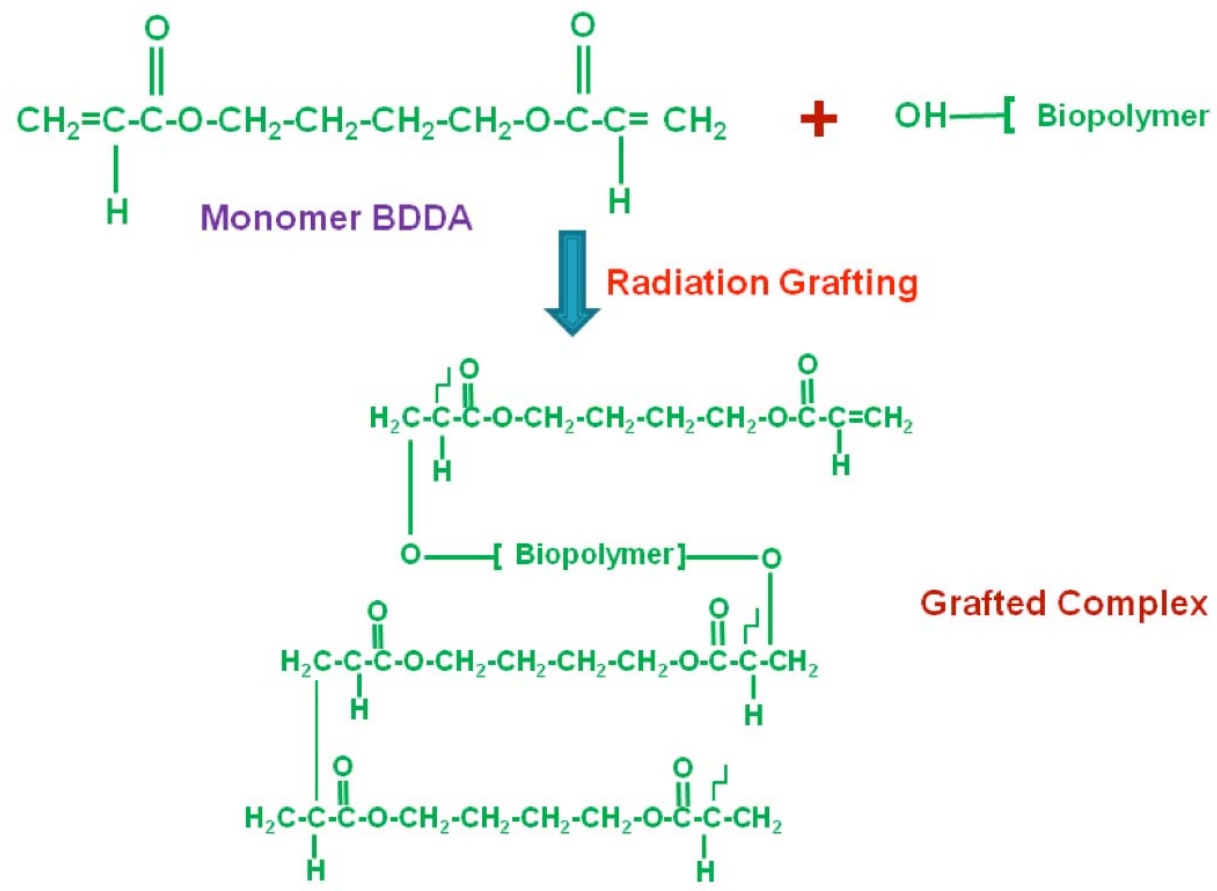

Figure 3: The proposed reaction mechanism between biopolymers (chitosan and starch) and BDDA monomer during gamma radiation. 


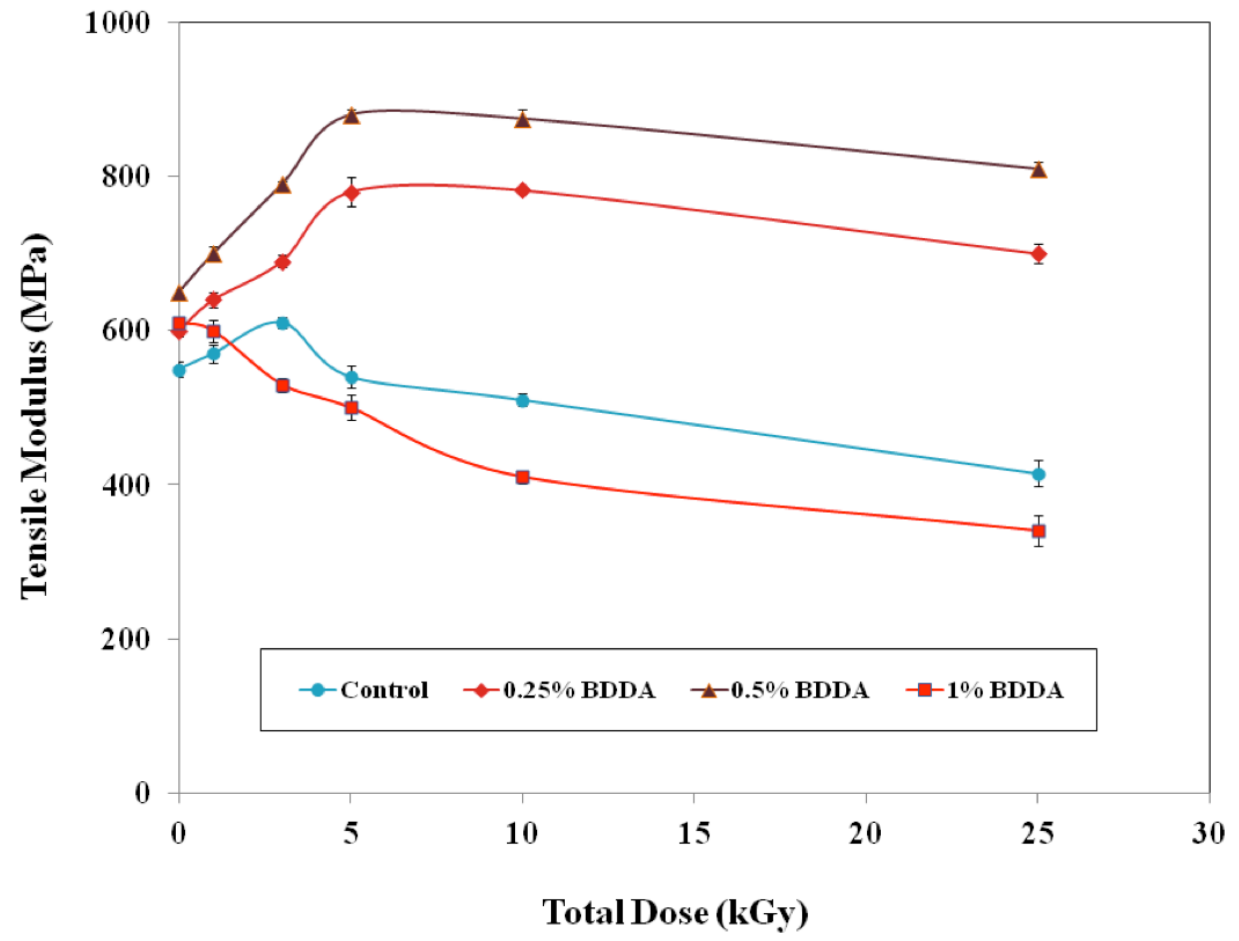

Figure 4: Effect of gamma radiation on tensile modulus of starch+chitosan (50:50) films (control), and BDDA containing starch+chitosan-based films.

function of gamma radiation is plotted at Figure 5 . Flexibility and elasticity of the films are essential parameters that are considered during the application of the polymeric films for packaging. These two phenomena are related to the elongation at break of the film. The Eb value of chitosan/starch-based films was found to be $16 \%$. With the increase of radiation dose, a monotonous reduction of $\mathrm{Eb}$ values were observed for control film (at $25 \mathrm{kGy}$, the Eb was only $6 \%$ ). Addition of BDDA (denoted as $0 \mathrm{kGy}$ in the figure) in the chitosan/starch-based films, the flexibility of the films also decreased significantly, as expected because TS and TM values were found to increase. The chitosan/starch-based films containing $0.25 \%, 0.50 \%$, and $1 \%$ BDDA, the Eb values were found to be 15, 14, and $12 \%$, respectively. For $0.50 \%$ BDDA, the Eb values were also found to decrease monotonously with the rise of radiation dose from 1 to $25 \% \mathrm{kGy}$. The decrease of Eb values at higher doses could be related to the radiation degradation of the film. When monomer BDDA was used, it might be graft copolymerized with the chitosan/starch molecules. When the films were irradiated, hydroxyl group of chitosan/starch could react with the acrylate group of BDDA resulted a cross-linked network. At high monomer concentrations, the Eb values were decreased drastically, the flexibility of the films was lowered because of the homo-polymer formation (poly-BDDA) or radiation degradation (breakage of the polymeric bonds) of the films.

\subsection{Water Vapor Permeability (WVP) of BDDA Containing Chitosan/Starch-Based Films}

Figure 6 shows the effect of BDDA on the WVP of chitosan/starch-based (50:50) films as a function of gamma radiation. WVP is a measure of ease of the moisture to penetrate and pass through a material. The WVP of chitosan/starch-based (50:50) film (termed as control) was found to be $2.45 \mathrm{~g} \cdot \mathrm{mm} / \mathrm{m}^{2} \cdot$ day $\cdot \mathrm{kPa}$. With the rise of gamma radiation from 1 to $25 \mathrm{kGy}$ doses, a monotonous decrease of WVP was observed. At 5 and 25 kGy doses, the WVP were found 2.20 and 1.7 $\mathrm{g} \cdot \mathrm{mm} / \mathrm{m}^{2} \cdot$ day $\cdot \mathrm{kPa}$, respectively. It indicated that due to exposure of gamma radiation, a network formed between two biopolymers which acted as a barrier to water vapor. Addition of monomer BDDA, followed by irradiation treatment, in chitosan/starch-based films showed a significant decrease of WVP and indicated better barrier properties. Incorporation of $0.25 \%$ BDDA, the WVP of chitosan/starch-based films reached to $1.80,1.65$, and $1.60 \mathrm{~g} \cdot \mathrm{mm} / \mathrm{m}^{2} \cdot$ day $\cdot \mathrm{kPa}$. Similarly, for the addition of $0.50 \%$ and $1 \%$ addition of BDDA monomer, the WVP values reduced significantly. A monotonous decrease of WVP indicated poor barrier to water vapors through the film. The monomer BDDA was expected to react with the biopolymers. The vinyl group of BDDA could chemically react with the hydroxyl group of chitosan and starch and thus a complex formed which helped to protect water vapor to penetrate into the films. 


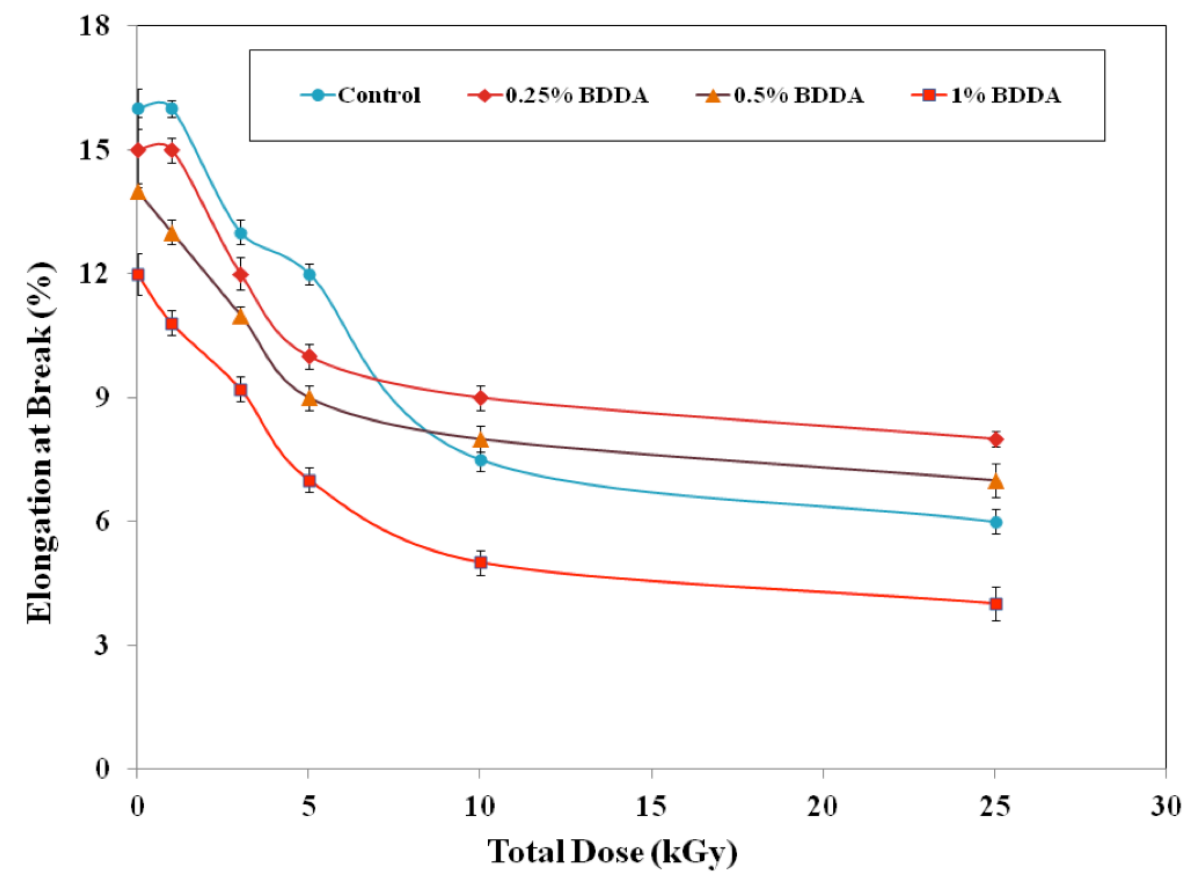

Figure 5: Effect of gamma radiation on elongation at break (\%) of starch+chitosan (50:50) films (control), and BDDA containing starch+chitosan-based films.

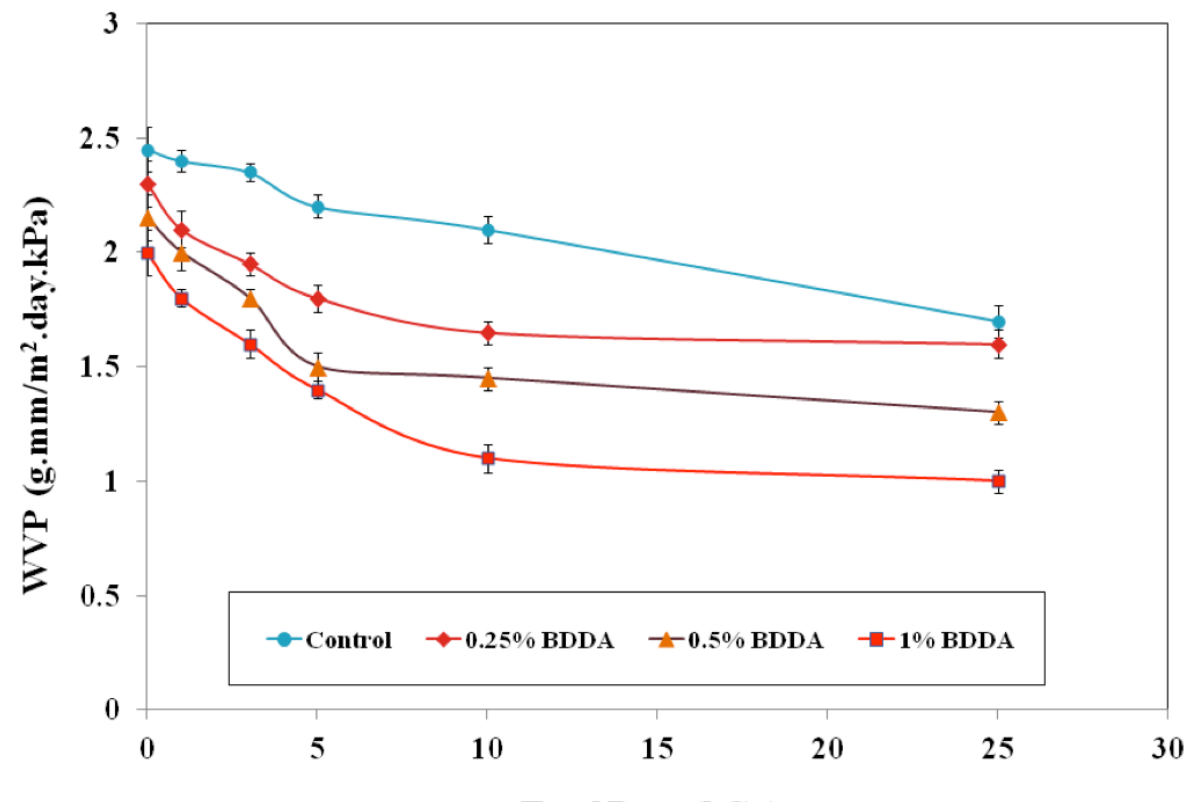

Total Dose (kGy)

Figure 6: Effect of gamma radiation on WVP of starch+chitosan (50:50) films (control), and BDDA containing starch+chitosanbased films.

\subsection{Structural Characterization by Fourier Transform Infrared Spectroscopy (FTIR)}

The FT-IR analysis was performed to determine the infrared bands and shifts related to chitosan-starch interactions, and also with monomer BDDA grafting by irradiation. Figure 7 represented the FT-IR spectrum of chitosan film. Two major peaks appeared at $1745 \mathrm{~cm}^{-1}$ and $1458 \mathrm{~cm}^{-1}$ designated to Amide-I and Amide-II, which characterized chitosan spectrum. The other important peaks of chitosan are visible at the wave number of $3007 \mathrm{~cm}^{-1}$ (intra- and intermolecular $\mathrm{O}-\mathrm{H}$ and $-\mathrm{CH}_{2} \mathrm{OH}$ vibrations), $2922 \mathrm{~cm}^{-1}$ (stretching $-\mathrm{NH}_{2}$ ), and $2312 \mathrm{~cm}^{-1}$ (symmetric and asymmetric $\mathrm{C}-\mathrm{H}$ vibrations). Moreover, the stretching $\mathrm{C}-\mathrm{N}$ vibration appeared at $1240 \mathrm{~cm}^{-1}$ and stretching $\mathrm{C}-\mathrm{O}$ band came 


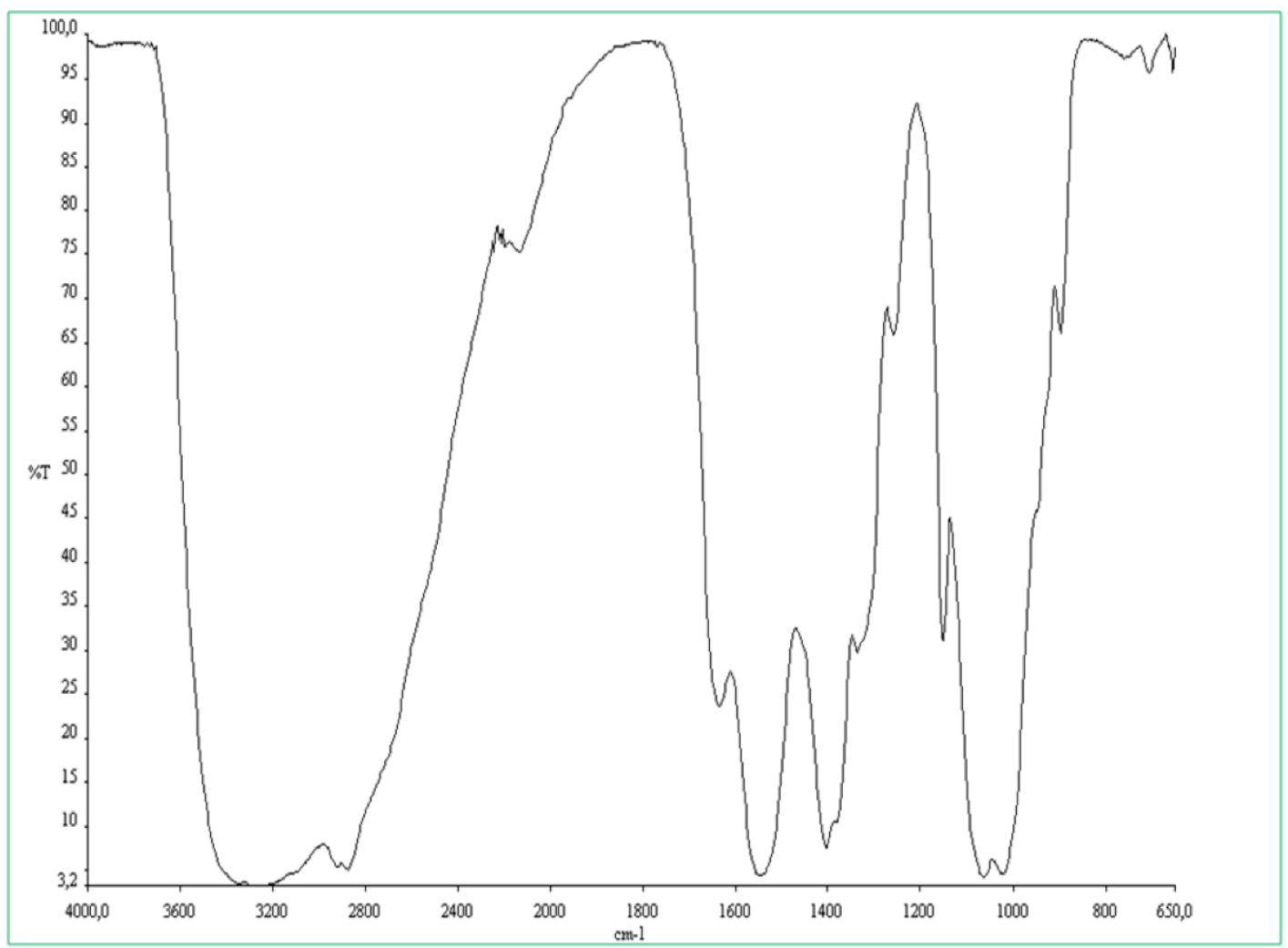

Figure 7: FT-IR spectrum of chitosan film.

at $1165 \mathrm{~cm}^{-1}$. In the non finger-print regions, peaks at $1095 \mathrm{~cm}^{-1}, 1025 \mathrm{~cm}^{-1}$, and $722 \mathrm{~cm}^{-1}$ appeared from the bound water of chitosan.

Chitosan was added as the reinforcing agent for starch-based films. To investigate the molecular interactions between chitosan and starch, FT-IR test was performed. Figure 8 depicted the FT-IR spectrum of chitosan/starch (50:50)-based film. Some differences were observed in the FT-IR spectrum after addition of chitosan in starch-based film. Here, Amide I peak became broad and Amide II peak showed a clear shoulder. The stretching $\mathrm{C}-\mathrm{N}$ vibration peak shifted to $1220 \mathrm{~cm}^{-1}$ and a new peak appeared at $1180 \mathrm{~cm}^{-1}$. The peak at $1160 \mathrm{~cm}^{-1}$ indicated the C-O stretching of the $\mathrm{C}-\mathrm{OH}$ group in starch. The characteristic peaks at 1090 $\mathrm{cm}^{-1}$ and $1045 \mathrm{~cm}^{-1}$ were attributed to C-O stretching of the $\mathrm{C}-\mathrm{O}-\mathrm{C}$ group in the anhydro-glucose ring. The peaks in the range $3600-3850 \mathrm{~cm}^{-1}$ attributed from O$\mathrm{H}$ groups present in chitosan and starch. From this investigation, this is clearly revealed that some molecular interactions occurred between chitosan and starch which indicated better homogenization of the biopolymers (chitosan and starch) used. There were no new peaks in the spectrum that indicated chitosan was not chemically bound with starch, as expected, but a nice bio-blend formed.
The monomer, 1,4-butanediol diacrylate (BDDA) was grafted to chitosan/starch-based film by gamma radiation. The spectrum is presented in Figure 9 . The film was irradiated at $5 \mathrm{kGy}$ dose. A major change in most of the peak positions is observed. Both Amide-I $\left(1745 \mathrm{~cm}^{-1}\right)$ and Amide-II $\left(1458 \mathrm{~cm}^{-1}\right)$ peaks shifted to lower frequencies indicated molecular interactions of BDDA with chitosan. The vinyl group of BDDA is highly reactive and could make a grafted complex with the hydroxyl group of chitosan. The major peaks of starch $\left(1160 \mathrm{~cm}^{-1}, 1090 \mathrm{~cm}^{-1}\right.$, and $\left.1045 \mathrm{~cm}^{-1}\right)$ also changes and proved that both the biopolymers reacted with monomer BDDA during irradiation. New peaks also appeared for BDDA and poly(BDDA). The peaks in the range of $3800-3200 \mathrm{~cm}^{-1}$ are assigned to the stretching vibrations of $\mathrm{O}-\mathrm{H}$ group present in biopolymers. The most important peak of BDDA is $\mathrm{C}=\mathrm{O}$ group in ester linkage, which appeared at $1720 \mathrm{~cm}^{-1}$. Other important peak of BDDA is vinyl group $\left(-\mathrm{CH}=\mathrm{CH}_{2}\right)$, become visible at $1632 \mathrm{~cm}^{-1}$. Two other peaks also appeared at $1295 \mathrm{~cm}^{-1}$ and $1162 \mathrm{~cm}^{-1}$, represented anti-symmetric $\mathrm{C}-\mathrm{O}-\mathrm{C}$ esters and $\mathrm{C}-\mathrm{C}-\mathrm{O}-$ groups present in BDDA. A comparison between three types of $\mathrm{FT}$-IR spectrum is given in Figure 10. From this FT-IR spectrum, this is clearly revealed that monomer BDDA grafted with chitosan and starch during exposure of gamma radiation. 


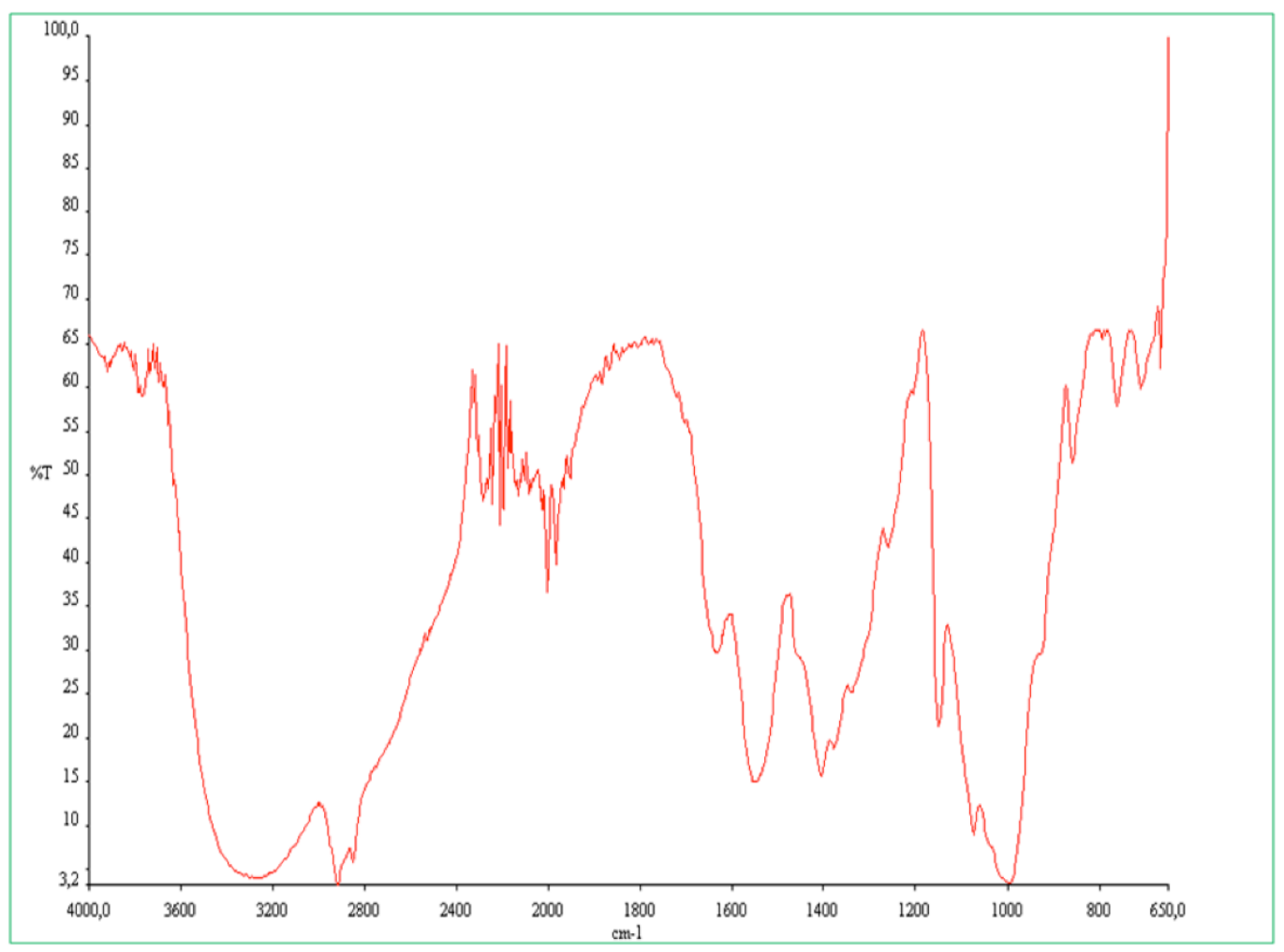

Figure 8: FT-IR spectrum of chitosan/starch (50:50)-based film.

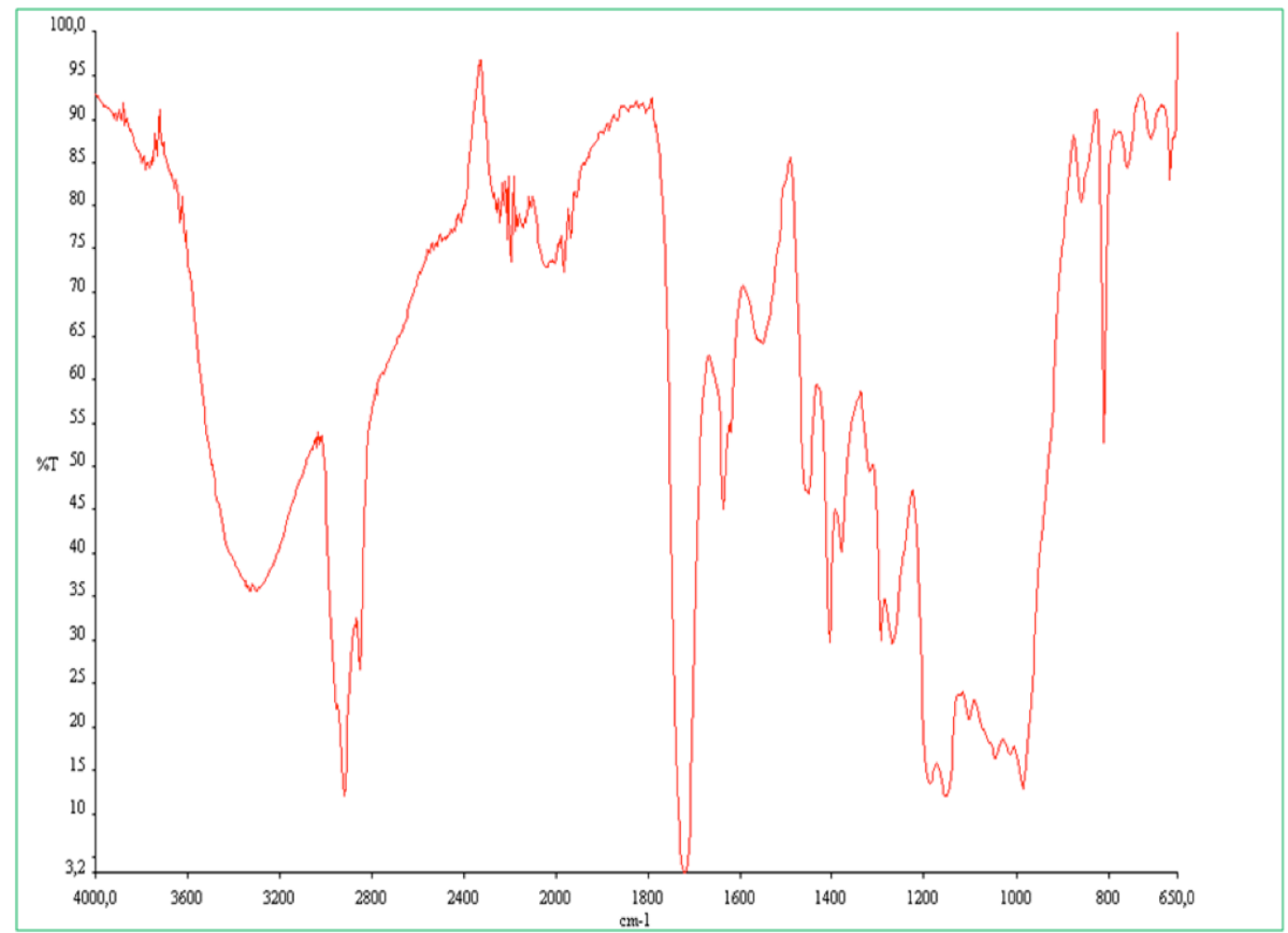

Figure 9: FT-IR spectrum of BDDA grafted to chitosan/starch-based film by gamma radiation.

\subsection{Water Uptake of the Films}

The water uptake behavior of chitosan film, chitosan/starch (50:50) film, and BDDA grafted (0.5 wt\%, at $5 \mathrm{kGy}$ ) chitosan/starch film are shown in Figure 11. It was found that water uptake of BDDA grafted starch/chitosan films were much lower compared to 


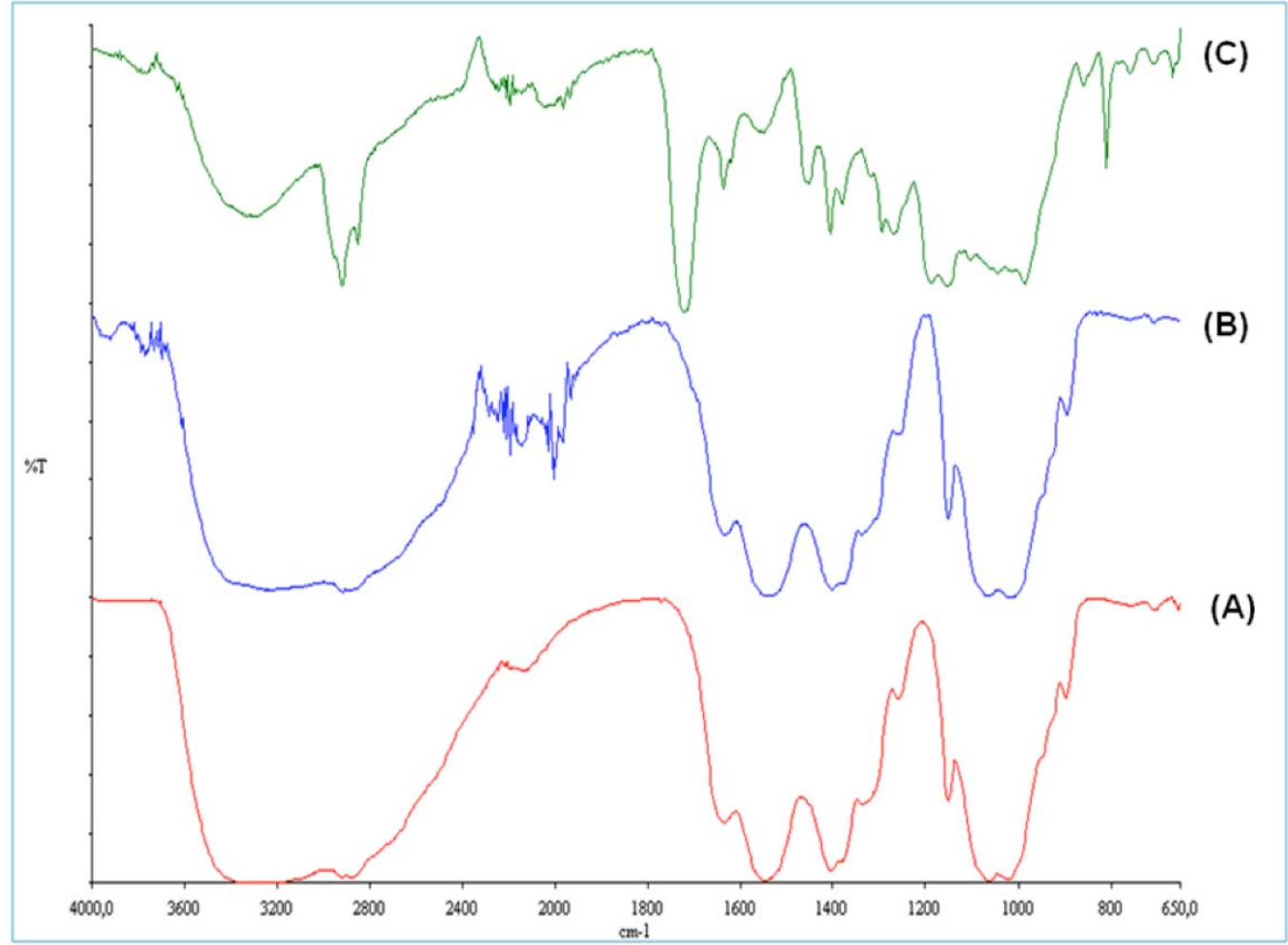

Figure 10: Comparison of FT-IR spectra (A-chitosan; B-chitosan/starch; and C-BDDA grafted chitosan/starch).

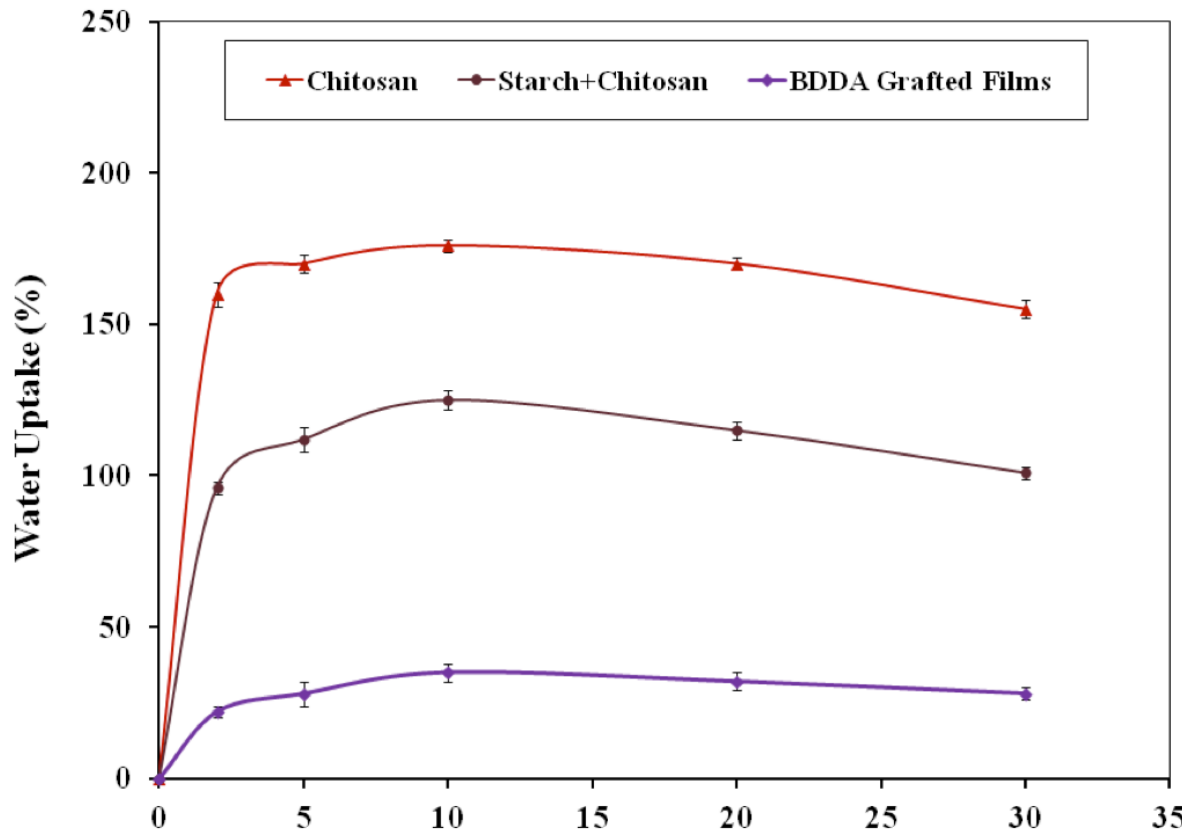

Soaking Time (min)

Figure 11: Water uptake of chitosan, starch+chitosan (50:50), and BDDA (0.5 wt\%) grafted (at 5 kGy) starch+chitosan (50:50) films.

starch/chitosan and native chitosan films. Both chitosan and chitosan/starch films absorbed water very rapidly. After 2 min, grafted film absorbed $22 \%$ water but chitosan film absorbed $160 \%$ water. On the other hand, starch/chitosan film absorbed $96 \%$ water. At $10 \mathrm{~min}$; grafted, chitosan and chitosan/starch films reached to $35 \%, 176 \%$, and $125 \%$ of water uptake. After $10 \mathrm{~min}$ of immersion, then both chitosan and chitosan/starch 


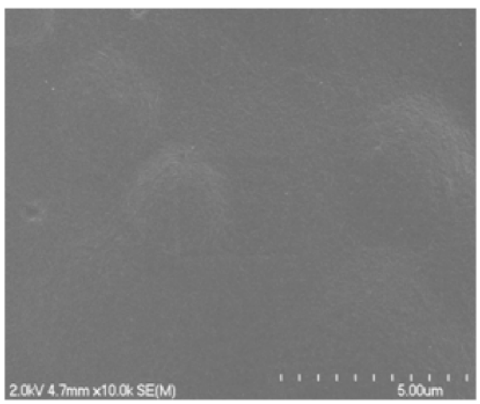

(a)

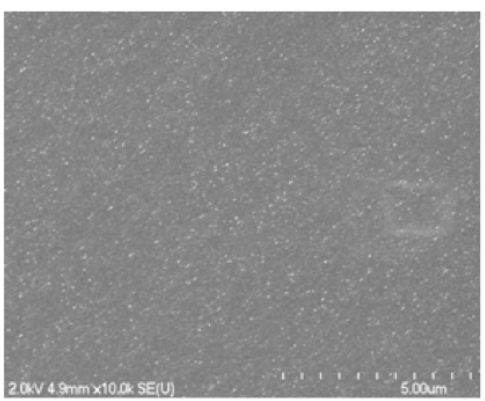

(b)

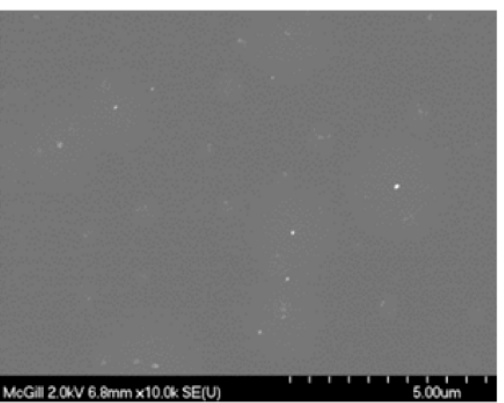

(c)

Figure 12: SEM images of chitosan (a), chitosan+starch (50:50) (b), and BDDA (0.5 wt\%) grafted (at 5 kGy) chitosan+starch (50:50) (c) films.

films showed a monotonous decrease of water uptake and indicated the loss of its mass. But BDDA grafted films were almost static. After $30 \mathrm{~min}$, the water uptake of BDDA grafted, native chitosan and starch/chitosan films reached to $28 \%, 155 \%$, and $101 \%$. Chitosan is water soluble as the salts of various acids present in Dglucosamino unit. The BDDA grafted starch/chitosan film had better stability in water compared to chitosan or chitosan/starch-based films. The monomer might be reacted with the biopolymers (chitosan and starch) and formed network, which prevented water molecules into the films.

\subsection{Investigation of Morphological Properties Using SEM}

Figure 12 represented the surface morphology of the films investigated by SEM. The images of chitosan (a), chitosan+starch (50:50) (b) and BDDA (0.5 wt\%) grafted (at 5 kGy) chitosan+starch (50:50) (c) films are presented here. The surface of chitosan films (a) appeared a homogenous, smoother and denser film surface with no gross defects. The smooth and homogenous surface of the films is an indicator of the structural integrity of the observed films, and thus good mechanical properties were obtained. It also indicated better solubilization and homogenization of chitosan in aqueous medium. But chitosan/starch-based films showed rough and irregular surface with bubbles as compared to pure chitosan films. It indicated that the biopolymers were not reacted. It was just a bio-blend. Here, chitosan was acted as a reinforcing agent. Interestingly, the surface of the BDDA grafted chitosan/starch-based films (c) appeared to be clean and much better compared to chitosan/starch-based films (b). It pointed out that BDDA reacted with the biopolymers. The appearance of the BDDA grafted films significantly improved which is a major novelty of this investigation.

\section{CONCLUSIONS}

Chitosan/starch-based biodegradable films were prepared by solution casting. The optimum content of chitosan was found to be $50 \%$ (by wt.) in starch-based films. Chitosan acted as an excellent reinforcing agent. Monomer 1,4 butanediol diacrylate (BDDA) was added to the starch/chitosan (50:50)-based film then irradiated using gamma radiation. The BDDA treated films improved the mechanical (strength and modulus) and barrier properties (water vapor permeability) compared to native chitosan/starch-based films. Molecular interactions were observed due to incorporation of BDDA, and were confirmed by FTIR spectroscopy. The BDDA treated films became more hydrophobic in nature. Moreover, the appearance of the BDDA treated films also improved compared to chitosan or chitosan/starch-based films. From this investigation, it can be concluded that monomer BDDA was successfully formed an interpenetrating 3D networks under gamma radiation to chitosan/starch-based biodegradable films.

\section{REFERENCES}

[1] Khan RA, Salmieri S, Dussault D, Calderon JU, Kamal MR Safrany A, Lacroix M. Production and properties of nanocellulose-reinforced methylcellulose-based biodegradable films. J Agric Food Chem 2010; 58: 7878-85. http://dx.doi.org/10.1021/jf1006853

[2] Khan RA, Salmieri S, Dussault D, Sharmin N, Lacroix M. Mechanical, barrier and interfacial properties of biodegradable composite films made of methylcellulose and PCL. J Appl Polym Sci 2012; 123(3): 1690-97. http://dx.doi.org/10.1002/app.34655

[3] Sharmin N, Khan RA, Salmieri S, Dussault D, Bouchard J, Lacroix M. Modification and characterization of biodegradable methylcellulose films with trimethylolpropane trimethacrylate (TMPTMA) by gamma radiation: Effect of nanocrystalline cellulose. J Agric Food Chem 2012; 60(2): 623-29. http://dx.doi.org/10.1021/ji203500s

[4] Yang SY, Liu CI, Wu JY, Kuo JC, Huang CY. Improving the processing ability and mechanical strength of 
starch/poly(vinyl alcohol) blends through plasma and acid modification. Macromolecular Symposia 2008; 272: 150-55. http://dx.doi.org/10.1002/masy.200851222

[5] Tang $\mathrm{H}$, Xiong $\mathrm{H}$, Tang $\mathrm{S}$, Zou $\mathrm{P}$. A starch-based biodegradable film modified by nano silicon dioxide. J Appl Polym Sci 2009; 113: 34-40. http://dx.doi.org/10.1002/app.29855

[6] Zaman HU, Khan MA, Khan RA, Pervin S, Al-Mamun M. A comparative study between Gamma and UV Radiation of jute fabrics/polypropylene composites: Effect of starch. J Reinfor Plast Compos 2010; 29(13): 1930-39. http://dx.doi.org/10.1177/0731684409343325

[7] Haydaruzzamnan, Khan AH, Hossain MA, Khan MA, Khan RA, Hakim MA. Fabrication and characterization of jute reinforced polypropylene composite: Effectiveness of coupling agents. J Compos Mater 2010; 44(16): 1945-63. http://dx.doi.org/10.1177/0021998309356604

[8] Bao J, Jin L, Xiao P, Shen S, Sun M, Corke H. Starch physicochemical properties and their associations with microsatellite alleles of starch-synthesizing genes in a rice RIL population. J Agric Food Chem 2008; 56: 1589-94. http://dx.doi.org/10.1021/j073128+

[9] Chen CJ, Shen YC, Yeh Al. Physico-chemical characteristics of media-milled corn starch. J Agric Food Chem 2010; 58: 9083-91.

http://dx.doi.org/10.1021/jf1020945

[10] Siddaramaiah, Baldev R, Somashekar R. Structure-property relation in polyvinyl alcohol/starch composites. J Appl Polym Sci 2004; 91: 630-35. http://dx.doi.org/10.1002/app.13194

[11] Chen MC, Yeh GHC, Chiang BH. Antimicrobial and physicochemical properties of methylcellulose and chitosan films containing a preservative. J Food Process Preserv 1996; 20: 379-90. http://dx.doi.org/10.1111/j.1745-4549.1996.tb00754.x

[12] Majeti NV, Kumar RA. Review of chitin and chitosan applications. J React Funct Polym 2000; 46: 1-27. http://dx.doi.org/10.1016/S1381-5148(00)00038-9

[13] Shahidi F, Arachchi JKV, Jeon Y. Food applications of chitin and chitosan. Trends Food Sci Technol 1999; 10: 37-51. http://dx.doi.org/10.1016/S0924-2244(99)00017-5
[14] Alam R, Khan MA, Khan RA. Study on the physicomechanical properties of photocured chitosan films with oligomer and acrylic monomer. J Polym Environ 2008; 16(3): 213-19.

http://dx.doi.org/10.1007/s10924-008-0099-2

[15] Helander IM, Nurmiaho-Lasilla EL, Ahvenainen R, Rhoade SJ, Roller S. Chitosan disrupts the barrier properties of the outer membrane of Gram-negative bacteria. Int J Food Microbiol 2001; 71: 235-44 http://dx.doi.org/10.1016/S0168-1605(01)00609-2

[16] Coma V, MartiaL-Gros A, Garreau S, Copinet A, Salin F, Deschamps A. Edible antimicrobial films based on Chitosan matrix. J Food Sci 2002; 67: 1162-69. http://dx.doi.org/10.1111/j.1365-2621.2002.tb09470.x

[17] Pinotti A, Garcia MA, Martinoa MN, Zaritzkya NE. Study on microstructure and physical properties of composite films based on chitosan and methylcellulose. J Food Hydrocolloids 2007; 21: 66-72.

http://dx.doi.org/10.1016/j.foodhyd.2006.02.001

[18] Khan RA, Salmieri S, Dussault D, Calderon JU, Kamal MR, Safrany A, Lacroix M. (2012), Preparation, gamma-irradiation and thermo-mechanical characterization of chitosan-loaded methylcellulose films. J Polym Environ 2012; 20(1): 43-52. http://dx.doi.org/10.1007/s10924-011-0336-y

[19] Azeredo HMC, Mattoso LHC, Wood D, Williams TG, Bustillos RJA, McHugh TH. Nanocomposite edible films from mango puree reinforced with cellulose nano-fibers. J Food Sci 2009; 74 (5): $31-35$ http://dx.doi.org/10.1111/i.1750-3841.2009.01186.x

[20] Sanchez-Garcia MD, Lagaron JM. On the use of plant cellulose nanowhiskers to enhance the barrier properties of polylactic acid. Cellulose 2010; 17: 987-04. http://dx.doi.org/10.1007/s10570-010-9430-x

[21] Miller KS, Krochta JM. Oxygen and aroma barrier properties of edible films: A review. Trends Food Sci Technol 1997; 8(7): 228-37. http://dx.doi.org/10.1016/S0924-2244(97)01051-0

[22] Khan RA, Parsons AJ, Jones IA, Walker GS, Rudd CD. Surface treatment of phosphate glass fibers using 2hydroxyethyl methacrylate: Fabrication of polycaprolactone based composites. J Appl Polym Sci 2009; 111(1): 246-54. http://dx.doi.org/10.1002/app.29050 